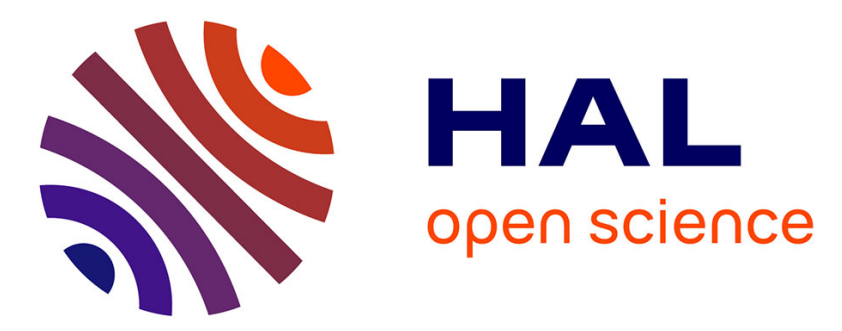

\title{
Near-infrared light-responsive UCST-nanogels using an efficient nickel-bis(dithiolene) photothermal crosslinker
}

\author{
Amélie Augé, Franck Camerel, Apolline Benoist, Yue Zhao
}

\section{To cite this version:}

Amélie Augé, Franck Camerel, Apolline Benoist, Yue Zhao. Near-infrared light-responsive UCSTnanogels using an efficient nickel-bis(dithiolene) photothermal crosslinker. Polymer Chemistry, 2020, 11 (23), pp.3863-3875. 10.1039/d0py00567c . hal-02928565

\section{HAL Id: hal-02928565 \\ https://hal.science/hal-02928565}

Submitted on 9 Sep 2020

HAL is a multi-disciplinary open access archive for the deposit and dissemination of scientific research documents, whether they are published or not. The documents may come from teaching and research institutions in France or abroad, or from public or private research centers.
L'archive ouverte pluridisciplinaire HAL, est destinée au dépôt et à la diffusion de documents scientifiques de niveau recherche, publiés ou non, émanant des établissements d'enseignement et de recherche français ou étrangers, des laboratoires publics ou privés. 


\title{
Near-Infrared Light-Responsive UCST-Nanogels Using an Efficient Nickel-bis(dithiolene) Photothermal Crosslinker
}

\author{
Amélie Augé ${ }^{a}$, Franck Camerel ${ }^{b}$, Apolline Benoist $^{c}$ and Yue Zhao*a
}

\begin{abstract}
A new kind of near-infrared (NIR) light-responsive polymer nanogels is demonstrated. The micellar aggregates of an ABA-type triblock copolymer, whose core is a thermosensitive polymer displaying an upper-critical-solution-temperature (UCST), are crosslinked using a photothermal nickel-bis(dithiolene) complex that absorbs NIR light and converts efficiently optical energy to heat. We show that when the nanogel aqueous solution is exposed to NIR light, even at low power density of $0.16 \mathrm{~W} / \mathrm{cm}^{2}$ and low nickel-bis(dithiolene) complex concentration of $61,4 \mu \mathrm{g} / \mathrm{mL}$, the photothermally induced heating is sufficient to allow the nanogel particles to undergo a volume phase transition. The induced volume increase due to the positive thermosensitivity of the polymer leads to release of loaded hydrophobic dye molecules. Using an energy balance model, the photothermal conversion efficiency of the nickel-bis(dithiolene) complex in the nanogel was evaluated through solution temperature and transmittance measurements under NIR laser irradiation at various light power densities as well as different nanoparticle concentrations and solvents. The photothermal conversion efficiency can reach about $64 \%$, which positions the nickelbis(dithiolene) complex among the most efficient photothermal agents in the NIR spectral region around $1000 \mathrm{~nm}$.
\end{abstract}

\section{Introduction}

The development of proteomic methods allowed for identifying many therapeutic targets and consequently guided research for the development of new specific treatments ${ }^{1}$. However, some pharmacokinetic problems restrict the administration of the drugs (drug solubility, non-specific adsorption, premature clearance). Thus, the vectorization allows solubilizing and protecting the drug from administration site to therapeutic target, but also controlling the drug release. For this application, smart-materials, namely, materials able to modify their properties by external stimuli, are widely coveted. The controlled release induced by light attracts much attention since the drug release could be remote-controlled spatially and temporally ${ }^{2}$. Materials sensitive to near-infrared (NIR) light are more suitable for this application because NIR lights are weakly absorbed and diffused by biological tissues in comparison with visible

\footnotetext{
a. Laboratoire de Polymères et Cristaux Liquides, Département de Chimie, Université de Sherbrooke, Sherbrooke, Québec, Canada.

*E-mail :yue.zhao@usherbrooke.ca

${ }^{b .}$ Institut des Sciences Chimique de Rennes - UMR 6226, Université de Rennes, 35000 , France

c. Laboratoire de Biogéochimie Terrestre, Département de chimie, Université de Sherbrooke, Québec, Canada

+ Electronic Supplementary Information (ESI) available: Synthesis of $\mathrm{Ni}\left(\mathrm{SC}_{10} \mathrm{Styr}\right)_{4}$ AOMC and BTC. Methodology for elemental analysis by ICP-MS. Methodology for determination of photothermal conversion efficiency (Fig. S1-S2). Calibration curve of Nile Red by fluorescence (Fig. S3). Chromatograms of PDMA and PDMA-UCST (Fig. S4). FTIR and ${ }^{1} \mathrm{H}-\mathrm{NMR}$ spectra of PDMA, PDMA-UCST and PDMA-UCST-C2 (Fig. S5) TEM picture of PDMA-UCST-C1 (Fig. S6). Temperature profiles over time for PDMA UCST-C1 (Fig. S7). Fluorescent spectra of Nile Red release over time for PDMA-UCSTC1 and PDMA-UCST-C2 (Fig. S8). See DOI: 10.1039/x0xx00000x
}

and UV light ${ }^{3-5}$. Thus, the radiation could penetrate tissue and activate the photosensitive material. Several mechanisms are possible for controlled release such as photo-isomerization ${ }^{6}$, photorearrangement ${ }^{7}$, photolysis ${ }^{8}$, photo-oxidation ${ }^{9}$, use of upconversion nanoparticles $^{10,11}$ and photothermal effect. Photothermal effect based on conversion of radiative energy to heat is particularly interesting for non-invasive medicine ${ }^{12,13}$. Indeed, this effect can be used directly for photothermal treatment $\left(T>45^{\circ} \mathrm{C}\right)$ or in combination with chemotherapy $\left(\mathrm{T}^{\sim} 39-42^{\circ} \mathrm{C}\right)$. Four types of materials are usually employed to generate photothermal effect. (1) Organic polymers and dyes ${ }^{14}$ such as polyaniline ${ }^{15}$, polypyrrole ${ }^{16}$, Indocyanine green (IR 125) $)^{17}$, iodide dye (IR 780) ${ }^{18}$, heptamethine indocyanine dye (IR 825$)^{19}$ or cypate ${ }^{20}$. These compounds are usually charged into micelles due to their weak solubility and stability in aqueous solutions. (2) Metal nanostructures ${ }^{21-23}$, particularly goldnanorods of varying aspect ratios for surface plasmon resonance (SPR) in the NIR region. However, the SPR band is very sensitive to environment (refractive index, dielectric constant,...) and the photothermal conversion efficiency are often different between in vitro and in vivo assays. In addition, gold nanorods are not stable under laser irradiation and suffer from low clearance ${ }^{24}$. (3) Compounds based on carbon ${ }^{25}$ (graphene, carbon nanotubes) and (4) materials based on copper or molybdenum chalcogenide semiconductors $^{26-29}$.

In order to combine photothermal effect and chemotherapy, some studies reported stimuli- responsive nanoparticles for which the phase transition - leading to release of drug - takes place through the heat generated by absorption of NIR-light ${ }^{8,30-32}$. For nanosystems combining both NIR photothermal material and thermosensitive 
polymer, the increase of temperature due to the light-to-heat conversion, leads to the dilatation of polymer matrix for polymer having UCST (Upper Critical Solution Temperature) ${ }^{33,34}$, or the collapse of matrix for polymer having LCST (Lower Critical Solution Temperature $)^{35,36}$. In the first case, the drug can be released by diffusion while in the second case, the drug release takes place due to steric interference between shrinking polymer and drug. While many reports can be found for LCST-nanovectors sensitive to NIRlight ${ }^{37-40}$, studies of NIR-sensitive nanovectors based on UCST polymers are rare. Recently, Wu et al. loaded $\mathrm{Fe}_{3} \mathrm{O}_{4}$ nanoparticles in UCST micelles based on poly(acrylamide-co-acrylonitrile), investigated the photothermal effect by varying the $\mathrm{Fe}_{3} \mathrm{O}_{4}$ concentration under exposure to NIR-light $(808 \mathrm{~nm})$ for light power density of $2 \mathrm{~W} / \mathrm{cm}^{2}$, and showed the phase transition of the UCST copolymer upon NIR light induced temperature increase ${ }^{41}$. In another study, Tian et al. have used the same thermosensitive copolymer but the micelles were loaded with IR780 photothermal dye ${ }^{42}$. Therefore, it is of interest to develop new NIR light-responsive UCST polymer nanoparticles through efficient photo-to-heat conversion.

It has been demonstrated that nickel-bis(dithiolene) complexes are highly efficient and stable molecular photothermal agents ${ }^{43,44}$. More recently, nickel-bis(dithiolene) complexes were physically entrapped in the lipid bilayer of small unilamellar liposomes and a fine control of fluorophore or drug release from these nanostructures in solution could be achieved under NIR laser irradiation ${ }^{45}$ Additional studies have also shown that nickel-bis(dithiolene) complexes do not produce singlet oxygen under NIR irradiation, which is highly suitable to preserve the integrity of the drug, and that the incorporation of nickel-bis(diothiolene) complexes does not increase the cytotoxicity of the organic nanoparticles. A nickel-bis(dithiolene) complex was also physically entrapped in biocompatible block-copolymer nanoparticles of PEG-b-PMLABe, and it was shown that, under laser irradiation in the NIR region, on-demand delivery of doxorubicin from those non-toxic polymer nanoparticles could also be achieved in solution ${ }^{46}$.

In this paper, we report the synthesis and study of NIR lightresponsive UCST-nanogels based on poly(acrylamide-coacrylonitrile) (PAAm-co-AN) covalently crosslinked with a photothermally active nickel-bis(dithiolene) complex (Fig. 1). The positive thermosensitivity of PAAm-Co-AN is explained by formation/disruption of hydrogen bonds upon change in temperature ${ }^{47,48}$, and it has appealing features such as a low sensitivity of its phase transition temperature to variation of $\mathrm{pH}$ and/or ionic strength as well as easy tunability of its phase transition temperature by varying the molar ratio between acrylamide and acrylonitrile ${ }^{49-51}$. To crosslink UCST nanogels using photothermal NIR dye monomer, a new nickel-bis(dithiolene) complex carrying four styrene moieties at the periphery was synthesized. Due to their unique optical and electrochemical properties as well as high stability to temperature, air and light, compounds based on nickel sulfide have been much studied for electronic applications ${ }^{52-54}$. Using the NIR light photothermal crosslinker, UCST nanogels were prepared, their thermosensitive properties were investigated by turbidimetry and light scattering measurements, and the photothermal efficiency was demonstrated by transmittance and temperature measurements under exposure to laser source for several power densities. The photothermal conversion efficiency ( $\eta$ ) was measured using the energetic balance model. Finally, loading and release of hydrophobic model dye was studied using fluorescent assays.

\section{Experimental}

\subsection{Materials}

The following reagents were purchased from Sigma-Aldrich: acrylamide (AAm), acrylonitrile (AN), N,N-dimethylacrylamide (DMA), 7-hydroxy-4-methylcoumarin (HOMC), azobisisobutyronitrile (AIBN), methacryloyl chloride, carbon disulfide, Nile Red (NR), sodium hydroxide $(\mathrm{NaOH}), \mathrm{N}, \mathrm{N}^{\prime}$-methylenebis(acrylamide) (MBA), and tetrapropylammonium hydrogen disulfate. The following solvents were purchased from Fisher: acetone, chloroform, dimethylsulfoxide (DMSO), ether, ethanol, methanol, toluene, hydrogen chloride. Deuterated DMSO (d6-DMSO) was purchased from Cambridge Isotope Laboratories Incorporation.

AAm and AIBN were purified by recrystallization in chloroform and methanol respectively. AN was purified by passing through a column filled with basic alumina. DMA was purified by reduced pressure distillation. The monomer 7-acryloyl-4-methylcoumarin (AOMC) and S, $S^{\prime}$-bis ( $\alpha, \alpha^{\prime}$-dimethyl- $\alpha^{\prime \prime}$-acetic acid)-trithiocarbonate (BTC) chain transfer agent were synthesized following reported methods, described in Supporting Information. The synthesis of the newly developed nickel-bis(dithiolene) complex carrying four styrene moieties $\left[\left(\mathrm{Ni}\left(\mathrm{SC}_{10} \mathrm{Styr}\right)_{4}\right]\right.$ is fully described in Supporting Information.

\subsection{Synthesis of Triblock Copolymers and Crosslinking}

As shown in Fig. 1, the synthesis of nanogels took place in three steps. The first two steps allowed for obtaining triblock copolymer having A-B-A structure due to the use of BTC as chain transfer agent. During the last step, the crosslinking took place by rebooting the polymerization in presence of $\mathrm{MBA}$ and $\mathrm{Ni}\left(\mathrm{SC}_{10} \mathrm{Styr}\right)_{4}$ as crosslinking agents.

\subsubsection{Synthesis of triblock copolymer}

A-B-A-type triblock copolymer was synthesized by RAFT polymerization using BTC as chain transfer agent. As Fig. 1 shows, the synthesis took place in two steps. First, water-soluble block " $A$ ", denoted PDMA, was synthesized. Then, PDMA was used as macroRAFT agent to grow the UCST central block "B" of PAAm-co-AN leading to triblock copolymer.

Synthesis of $\operatorname{poly}(\mathrm{N}, \mathrm{N}$-dimethylacrylamide-co-7-acryloyl-4methylcoumarin) block

In order to simplify the notation, this block will be denoted PDMA. In $25 \mathrm{~mL}$ round bottom flask, $1.967 \mathrm{~mL}$ DMA (19.1 mmol), $488 \mathrm{mg}$ AOMC (2.12 mmol), $14 \mathrm{mg} \mathrm{AIBN}(85.3 \mu \mathrm{mol})$ and $120 \mathrm{mg}$ BTC (425 $\mu \mathrm{mol})$ were dissolved in $10 \mathrm{~mL}$ DMSO. After three freeze-pump-thaw cycles, the mixture was placed in oil bath thermostated at $70^{\circ} \mathrm{C}$ during 12 hours. After polymerization, the copolymer was precipitated in ether-acetone mixture. The copolymer was recovered by centrifugation and dialyzed 5 days against water (MWCO: 3500 Da). Finally, the polymer was lyophilized.

\section{Synthesis of central block PAAm-Co-AN UCST triblock copolymer}


A

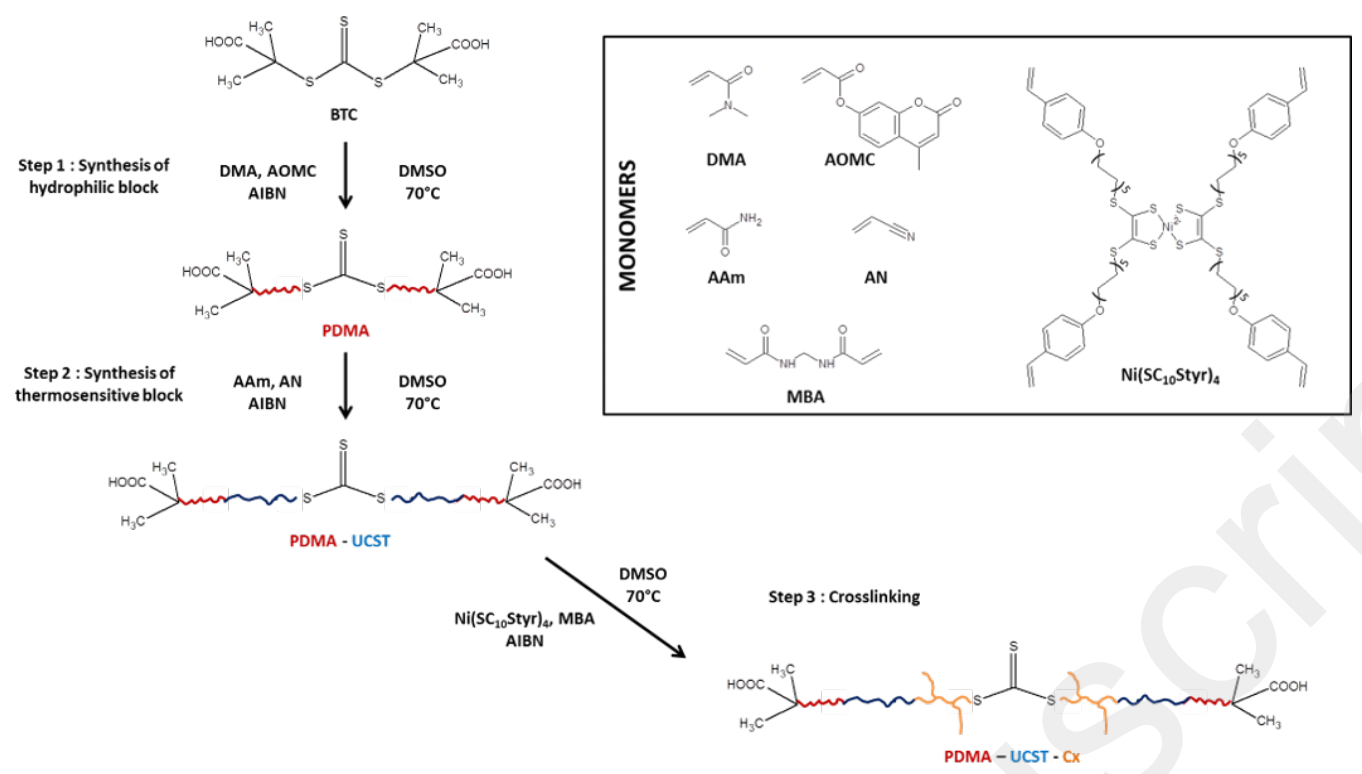

B

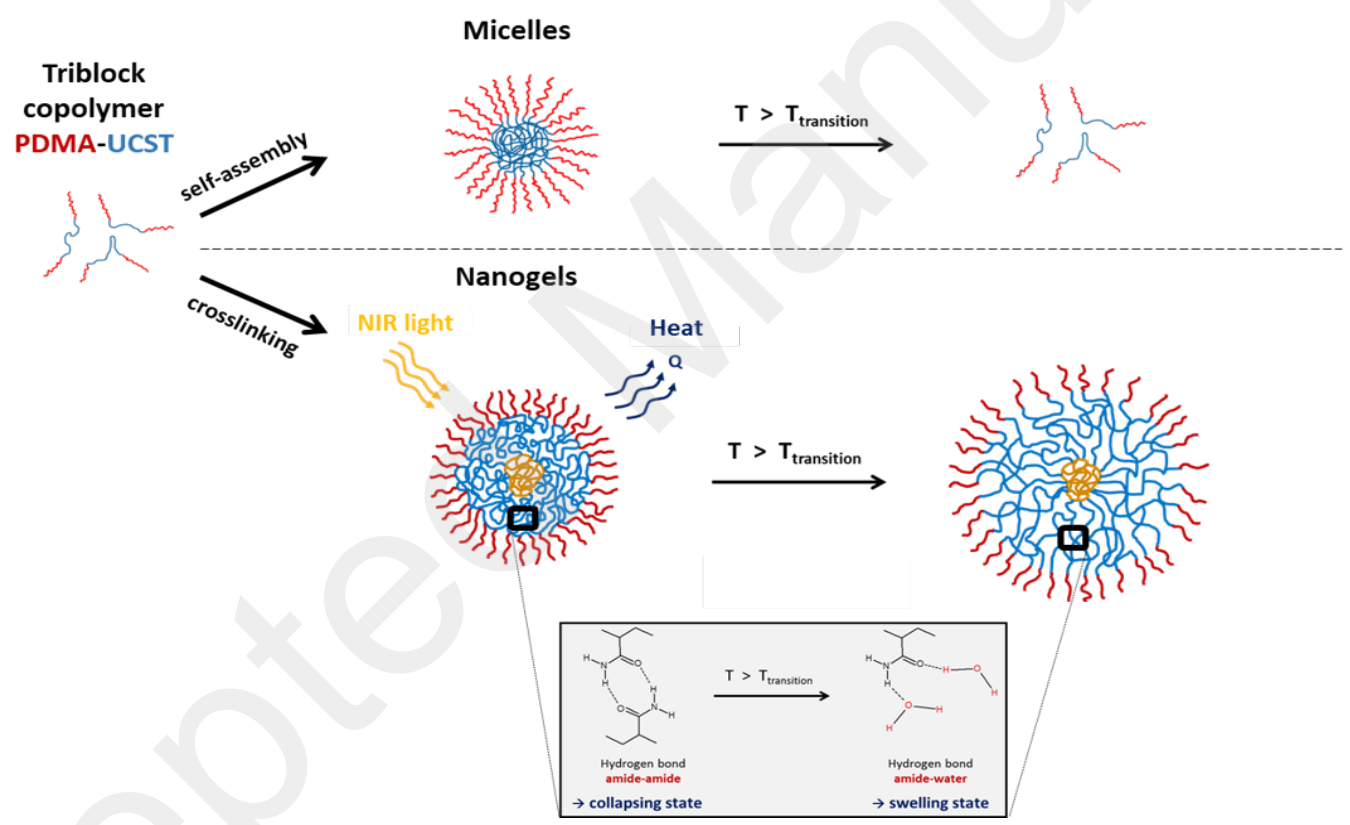

Fig. 1 (A) Synthetic steps to obtain the triblock copolymer and chemical structures of the monomers used. (B) Schematic showing the principle of conversion of light to heat by the crosslinked core based on nickel-bis(dithiolene) complex, leading to phase transition of the near-infrared light-responsive and thermosensitive copolymer nanogel.

This triblock copolymer was synthesized using PDMA as macro-RAFT agent. To simplify notation, the final triblock copolymer will be noted PDMA-UCST. In $25 \mathrm{~mL}$ round bottom flask, $100 \mathrm{mg}$ PDMA (15.7 $\mu \mathrm{mol}), 1.56 \mathrm{~g} \mathrm{AAm}(21.9 \mathrm{mmol}), 480 \mu \mathrm{L}$ AN ( $7.33 \mathrm{mmol}), 9.6 \mathrm{mg}$ AIBN ( $58.5 \mu \mathrm{mol}$ ) were dissolved in $20 \mathrm{~mL}$ DMSO. After three freeze-pumpthaw cycles, the mixture was placed in oil bath thermostated at $70^{\circ} \mathrm{C}$ during 8 hours. Following polymerization, the triblock copolymer was precipitated in acetone and recovered by centrifugation. The sample was purified by dialysis 5 days against water (MWCO: $3500 \mathrm{Da}$ ) and finally lyophilized.

\subsubsection{Crosslinking of triblock copolymer using the nickel-bis(dithiolene) complex}

The crosslinking took place by rebooting polymerization using PDMAUCST as RAFT macro-agent. Two samples were synthesized varying the molar ratio between $\mathrm{MBA}$ and $\mathrm{Ni}\left(\mathrm{SC}_{10} \mathrm{Styr}_{4}\right.$. For this, in $100 \mathrm{~mL}$ round bottom flask, $200 \mathrm{mg}$ PDMA-UCST were dissolved in $60 \mathrm{~mL}$ DMSO. After dissolution, $74 \mu \mathrm{mol}$ of the $\mathrm{Ni}\left(\mathrm{SC}_{10} \mathrm{Styr}_{4} / \mathrm{MBA}\right.$ mixture were added. Table 1 reports the two ratios $\mathrm{Ni}\left(\mathrm{SC}_{10} \mathrm{Styr}\right)_{4} / \mathrm{MBA}$ (denoted as Ni/MBA in Table 1) used for synthesize PDMA-UCST-C1 and PDMA-UCST-C2. 7,34 $\mu \mathrm{mol}$ and 14,32 $\mu \mathrm{mol}$ of Ni-complex were used for PDMA-UCST-C1 and PDMA-UCST-C2, respectively. The 
reaction solution was degassed by three freeze-pump-thaw cycles and placed in oil bath whose temperature was maintained to $70^{\circ} \mathrm{C}$. After polymerization, the nanogel suspension was purified by dialysis against water. The fraction of unreacted or un-encapsulated $\mathrm{Ni}\left(\mathrm{SC}_{10} \mathrm{Styr}\right)_{4}$ complex and MBA was removed by filtration (nylon 0.45 $\mu \mathrm{m})$. The sample was finally lyophilized.

\subsection{Characterizations}

\subsubsection{Structure of triblock copolymers and nanogels}

The number average molecular weight of PDMA and PDMA-UCST triblock copolymers were determined by size exclusion chromatography (SEC) at $45^{\circ} \mathrm{C}$ using Tosoh EcoSEC apparatus equipped with three TSK-GEL Super AWM-H columns and refractive index detector. DMSO was used as eluent $(0.3 \mathrm{~mL} / \mathrm{min})$. The copolymer concentration was $5 \mathrm{mg} / \mathrm{mL}$ and the injected volume was $10 \mu \mathrm{L}$. Poly(methyl methacrylate) was used for calibration.

The composition and structure of copolymers were studied by nuclear magnetic resonance (NMR). ${ }^{1} \mathrm{H}-\mathrm{NMR}$ spectra were recorded using Bruker BioSpin AG Ultrashield $300 \mathrm{MHz}$ spectrometer. d6 DMSO was used as deuterated solvent.

The suspension of nanogels was prepared by dispersing of dry nanogels in water or deuterated water at defined concentrations. To help the dispersion, the samples were submitted to sonication for 60 seconds.

UV-Visible spectra of nanogel suspensions ( $0.1 \mathrm{wt} \%$ in water and deuterated water) were recorded using Agilent Cary Series UV-VISNIR spectrophotometer. Particle morphology before and after crosslinking was observed using Hitachi $\mathrm{H}-7500$ transmission electron microscope (TEM) operating at $80 \mathrm{kV}$. Samples were prepared by depositing a drop of nanoparticles on copper grid covered with a carbon film. The excess solvent was removed immediately after deposition using absorbent paper. The content of $\mathrm{Ni}\left(\mathrm{SC}_{10} \mathrm{Styr}\right)_{4}$ complex was quantified by elemental analysis performed on a PerkinElmer ELAN DRC II ICP-MS equipped with an AS-93 autosampler. The sample preparation procedure is detailed in Supporting Information.

\subsubsection{Thermosensitive properties}

Thermosensitive properties of the triblock copolymer nanoparticles before and after crosslinking were studied by means of various optical techniques using a Peltier cell for temperature control and heat transfer. The transmittance, light scattering intensity, hydrodynamic diameter and polydispersity index of sample (0.1 wt\% in water) were recorded as the function of temperature during several heating-cooling cycles.

Measurements of solution transmittance as function of temperature were carried out using an Agilent Cary Series UV-VIS-NIR spectrophotometer. The transmittance was recorded at $400 \mathrm{~nm}$ every $1^{\circ} \mathrm{C}$ with a heating-cooling rate of $0.5^{\circ} \mathrm{C} / \mathrm{min}$. Dynamic light scattering (DLS) measurements were conducted using Malvern Nano ZS apparatus. The wavelength of incident light was $633 \mathrm{~nm}$ and the detection angle was $173^{\circ}$. Hydrodynamic diameter, light scattering intensity and polydispersity index were measured every $5^{\circ} \mathrm{C}$. The sample temperature was stabilized during 5 minutes before each measurement. Hydrodynamic diameters reported in this paper are extracted from size distribution in number.

\subsubsection{Evaluation of photothermal efficiency under laser irradiation}

The photothermal conversion efficiency of nanogels containing the nickel-bis(dithiolene) complex was investigated by monitoring temperature measurements under laser irradiation. The transmittance of the solution was also monitored during laser irradiation.

The transmittance measurements were carried out using two methods. In the first classical method, the sample temperature was maintained at $24.5^{\circ} \mathrm{C}$ using a Peltier cell. After thermal equilibrium, the temperature was increased at defined values with the Peltier cell and the transmittance was recorded every second until the targeted temperature is reached. In a second method, the sample temperature was maintained to $24.5^{\circ} \mathrm{C}$ using Peltier cell. Then, the laser source (MDL-H-980-4W, $980 \mathrm{~nm}$, Changchun New Industries Optoelectronics Tech. Co. Ltd) was placed in front of the sample solution and applied at several light powers. The temperature and transmittance were simultaneously recorded every 30s during 10 minutes. The temperature was recorded using a digital thermometer $\mathrm{HH} 11 \mathrm{C}$ Omega whose precision is $0.1^{\circ} \mathrm{C}$.

The transmittance and the temperature elevation under laser irradiation has been measured for several concentrations and laser power densities. The rise of temperature of pure water and pure deuterated water (in the absence of nanogels) was also recorded as reference using the same laser power densities.

The photothermal conversion efficiency was evaluated by determining the term $\eta$, corresponding to the ratio between energy dissipated as heat and radiative energy absorbed by sample. For these assays, $1.2 \mathrm{~mL}$ of nanogels dispersed in water or deuterated water at several concentrations were placed into quartz cell. To maintain a homogeneous temperature, a gentle magnetic stirring was applied. Then, the suspension was exposed to NIR-light at several light power densities. The sample temperature was recorded every 30 seconds during 10 minutes using digital thermometer placed into sample solution. The laser was then turned off and the temperature was also recorded every 30 seconds until sample returned to the room temperature. The photothermal conversion efficiency was determined using the energy balance model, proposed by Roper et al.. ${ }^{55}$ The details of the method are explained in Supporting Information.

Table 1 Characteristics of copolymers and nanogels

\begin{tabular}{|c|c|c|c|c|}
\hline Samples & $\begin{array}{c}\mathrm{M}_{\mathrm{n}}{ }^{\mathrm{a}} \\
\text { g. } \mathrm{mol}^{-1}\end{array}$ & $M_{w} / M_{n}^{a}$ & $\begin{array}{c}\text { Initial molar } \\
\text { ratio } \\
\mathrm{Ni} / \mathrm{MBA}\end{array}$ & $\begin{array}{l}{[\mathrm{Ni}]^{\mathrm{b}}} \\
\mu \mathrm{g} \cdot \mathrm{g}^{-1}\end{array}$ \\
\hline PDMA & 6400 & 1.11 & - & - \\
\hline PDMA-UCST & 57700 & 1.35 & - & - \\
\hline PDMA-UCST-C1 & - & - & 0.11 & 81.43 \\
\hline PDMA-UCST-C2 & - & - & 0.24 & 2582.46 \\
\hline
\end{tabular}

${ }^{a}$ Determined by SEC using poly(methyl methacrylate) as standard calibration

${ }^{\mathrm{b}}$ Determined by ICP-MS. The concentrations were given in $\mu \mathrm{g}$ of $\mathrm{Ni}$ per gram of dry nanogel. 
2.3.4. Loading and release experiments under NIR laser irradiation

The Nile Red loading was realized using the following procedure: 5 $\mathrm{mg}$ of dry nanogels were introduced in $800 \mu \mathrm{L}$ DMSO. Then, $200 \mu \mathrm{L}$ Nile Red (0.1 wt\% in DMSO) were added and after homogenization, the suspension was placed in dialysis against water. The uncharged fraction of Nile Red precipitated and was eliminated by filtration. The suspension was separated into many aliquots containing the same volume, and they were lyophilized. For release assays, $150 \mu \mathrm{L}$ of water were added into an aliquot to obtain a final concentration of $0.15 \mathrm{wt} \%$. The sample was then placed into a cup having dialysis membrane (MWCO: 12-14000 Da) in the bottom allowing the diffusion of small molecules. The cup was placed in quartz cell as shown in Fig. 7F. The release kinetic was monitored through a fluorescence spectroscopy. The fluorescence of Nile Red in the dialysate (F127 surfactant solution at $0.1 \mathrm{wt} \%$ in water) was recorded every 5 minutes during 4 hours with the sample exposed to several laser power densities. F127 surfactant was added to solubilize Nile Red molecules in the aqueous dialysate. Spectra were recorded using a Varian Cary Eclipse fluorimeter. The excitation wavelength was 565 $\mathrm{nm}$, and the emission wavelength range was $600-800 \mathrm{~nm}$. The excitation and emission slits were set at $20 \mathrm{~nm}$.

\section{Results and discussion}

3.1. Characterization of the nanogel particles before and after crosslinking

The number average molecular weight of PDMA and PDMA-UCST were determined by SEC and the results are gathered in Table 1. The chromatograms are shown in Fig. S4. The crosslinking of the copolymers leading to the nanogels was realized using PDMA-UCST as macro-RAFT agent for polymerization of $\mathrm{MBA}$ and $\mathrm{Ni}\left(\mathrm{SC}_{10} \mathrm{Styr}\right)_{4}$ at two ratios of $\mathrm{Ni}\left(\mathrm{SC}_{10} \mathrm{Styr}\right)_{4} / \mathrm{MBA}$ chosen based on the solubility limit in the reaction solution. To quantify the amount of crosslinker based on nickel complex, an elemental analysis was performed by ICP-MS. The concentrations determined are reported in Table 1. PDMA-UCSTC1 and PDMA-UCST-C2 contain, respectively, 81.43 and $2582.46 \mu \mathrm{g}$ of $\mathrm{Ni}$ per gram of dry nanogel. For the crosslinking polymerization, the total amount of crosslinker monomers was maintained constant, but for PDMA-UCST-C2, the quantity of Ni was twofold higher than for PDMA-UCST-C1. However, the concentrations of Ni determined by ICP-MS are in a ratio much higher than the expected ratio between the two samples. This observation can be explained on the one hand by the reactivity ratios which are difficult to predict for a complex system with a competition between the two crosslinkers. On the second hand, the more hydrophobic core of PDMA-UCST-C2 could load a higher quantity of $\mathrm{Ni}\left(\mathrm{SC}_{10} \mathrm{Styr}\right)_{4}$ complexes, which is supported by the presence of unreacted vinyl functions on the NMR spectrum shown in Fig. S5. Comparing the ${ }^{1} \mathrm{H}-\mathrm{NMR}$ spectra of PDMA, PDMA-UCST and PDMA-UCST-C2 (Fig. S5), the crosslinking is confirmed by the characteristic resonance peaks of $\mathrm{Ni}\left(\mathrm{SC}_{10} \mathrm{Styr}\right)_{4}$ complex at $1.27 \mathrm{ppm}$ corresponding to - $\mathrm{CH} 2$ - from alkyl chain, at 3.95 ppm for - $\mathrm{CH} 2-\mathrm{O}-\mathrm{Ph}$, at 5.11-5.65 and $6.54 \mathrm{ppm}$ for unreacted vinyl functions, and at $7.38 \mathrm{ppm}$ for $-\mathrm{H}$ of aromatic cycles. The TEM images in Fig. $2 \mathrm{~A}$ and $2 \mathrm{~B}$ confirm the presence of $\mathrm{Ni}\left(\mathrm{SC}_{10} \mathrm{Styr}\right)_{4}$ complex in the nanogels. After crosslinking, the contrast of the center of the spherical nanoparticles of PDMA-UCST-C2 is more important than the uncrosslinked PDMA-UCST micelles. This enhanced contrast, is explained by the higher electronic density of the nickel element in the nanogel particles. The same morphology was observed for PDMA-UCST-C1 (Fig. S6). The incorporation of the $\mathrm{Ni}\left(\mathrm{SC}_{10} \mathrm{Styr}\right)_{4}$ crosslinker in the nanogel can also be noticed from the absorption spectra in Fig. 2C. The presence of the nickel-bis(dithiolene) complex is evidenced by the characteristic NIR absorption band centered at $1050 \mathrm{~nm}$ observed in $\mathrm{H}_{2} \mathrm{O}$ and $\mathrm{D}_{2} \mathrm{O}$, which is absent for the PDMAUCST micelle solution (spectra not shown). It should be noted that $\mathrm{H}_{2} \mathrm{O}$ has a weak absorption band around $980 \mathrm{~nm}$ while $\mathrm{D}_{2} \mathrm{O}$ does not absorb in the NIR region. The absorption of $\mathrm{H}_{2} \mathrm{O}$ appears as a shoulder on the absorption band of PDMA-UCST-C2 in water.

\subsection{Thermosensitive properties}

The thermosensitive behavior of the nanoparticles before and after crosslinking was investigated by turbidimetry and by dynamic light scattering, and the results are presented in Fig. 3. For these measurements, the temperatures were set with a Peltier cell. Fig. $3 \mathrm{~A}$ and $3 \mathrm{~B}$ represent, respectively, the variation of transmittance and light scattering intensity as a function of temperature during the heating process for PDMA-UCST (green lines, circles), PDMA-UCSTC1 (red lines, squares) and PDMA-UCST-C2 (blue lines, triangles). For all samples, the transmittance increases while inversely the light scattering intensity decreases when the temperature increases, testifying the UCST behavior, i.e., a positive thermosensitivity. From these results, some remarks can be made. Firstly, for PDMA-UCST (uncrosslinked nanoparticles), the phase transition temperature is around $40-45^{\circ} \mathrm{C}$. Above the phase transition temperature, the transmittance basically reaches $100 \%$ and light scattering intensity attains almost zero. These observations are expected for UCST-kind micelles. Below phase transition temperature, the central thermosensitive block based on acrylamide and acrylonitrile is

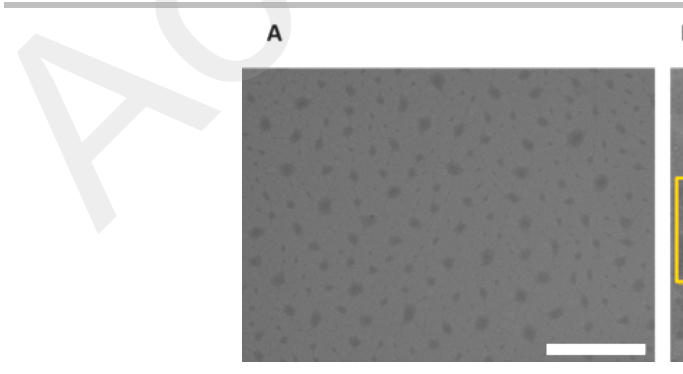

B

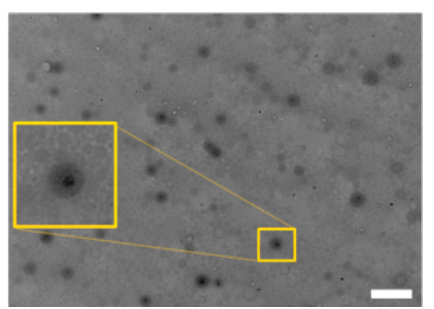

c

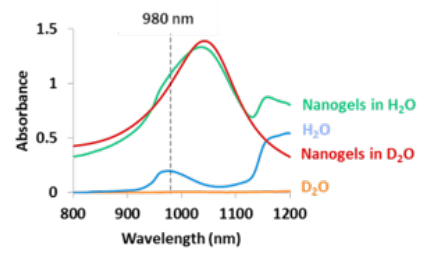

Fig. 2 (A) and (B) TEM images of PDMA-UCST and PDMA-UCST-C2 nanoparticles respectively (scale bars: $500 \mathrm{~nm}$ ). (C) Absorption spectra of water, deuterated water, PDMA-UCST-C2 in water and deuterated water at $0.1 \mathrm{wt} \%$. 
A

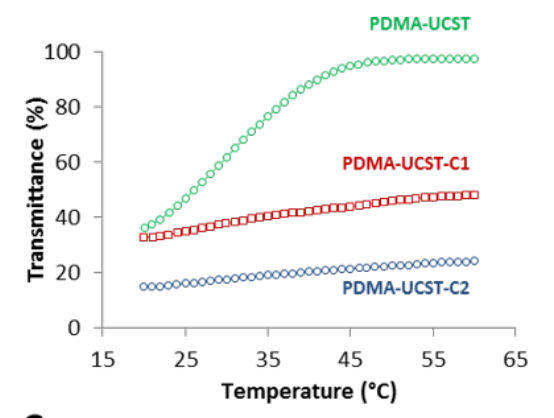

C

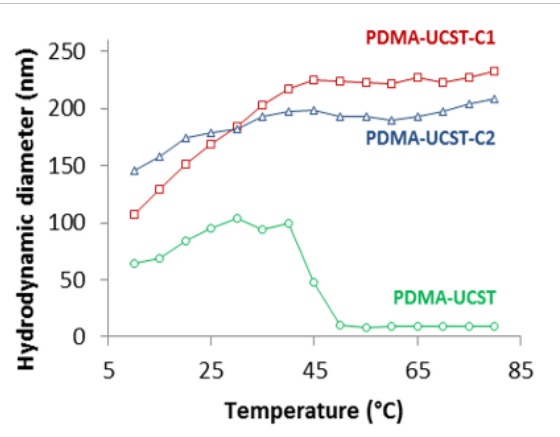

B

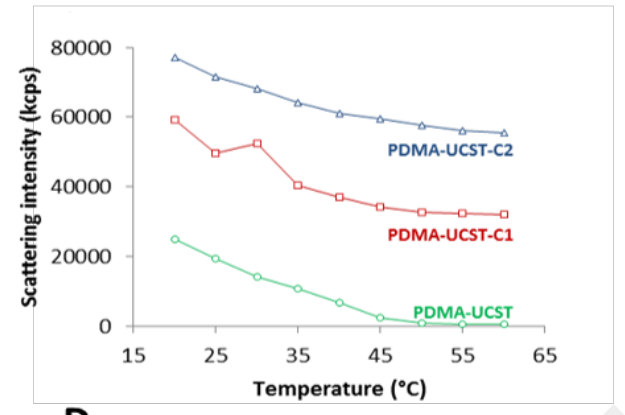

D

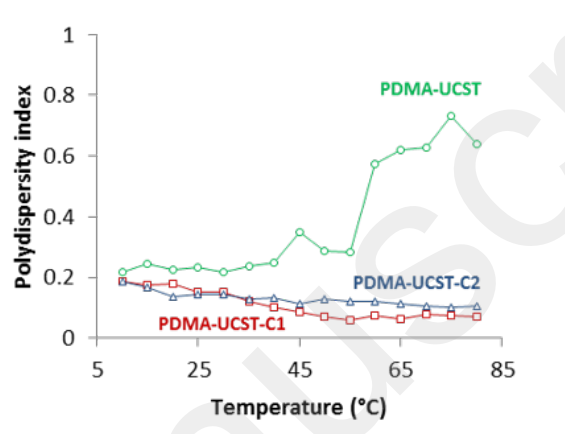

Fig. 3 Variation as a function of temperature during heating process for PDMA-UCST, PDMA-UCST-C1 and PDMA-UCST-C2 particles (0.1 wt\% in water) for: (A) solution transmittance, (B) light scattering intensity, (C) hydrodynamic diameter of micelle or nanogel particles, and (D) polydispersity index of the nanoparticles.

dehydrated due to favoured hydrogen bonding interactions between amide groups. These interactions lead to self-assembly of triblock copolymers into micelles in water, explaining the light scattering. By increasing temperature, hydrogen bonds between amide groups are gradually replaced by hydrogen bonds between amide group and water molecules. Due to this hydration, the central thermosensitive block becomes hydrophilic leading to dissociation of micelles beyond the phase transition temperature. The dissociation of nanoparticles results in maximal value of transmittance and minimal value of light scattering intensity. This dissociation is also highlighted in Fig. $3 \mathrm{C}$ showing the variation of hydrodynamic diameter as a function of temperature. Below the phase transition temperature, the particle diameter increases gradually from $65 \mathrm{~nm}$ to around $100 \mathrm{~nm}$ between 10 and $40^{\circ} \mathrm{C}$. In a previous study ${ }^{47}$, for micelles based on the same copolymer, this increase of volume before phase transition temperature was explained by the entrance of water inside nanoparticles like for UCST-nanogels. But beyond $45^{\circ} \mathrm{C}$, the diameter drastically drops to values below $10 \mathrm{~nm}$, corresponding to the dissociation of the micelles (see Fig. 1 uncrosslinked micelles).

The behavior of crosslinked nanogels is different. For PDMA-UCST-C1 and PDMA-UCST-C2, although the transmittance and light scattering intensity increases and decreases, respectively, with increasing temperature, they stay relatively low and high respectively, over the whole range of temperatures. This can be explained by the crosslinking efficiency using nickel-bis(dithiolene) and MBA as crosslinkers. Since the crosslinked nanoparticles are not able to dissociate, they diffuse light, even at high temperature when nanogels are swollen (see Fig. 1 crosslinked micelles). At temperatures below the phase transition, the transmittance and light scattering intensity for PDMA-UCST-C1 and PDMA-UCST-C2 nanogels are, respectively, lower and higher than PMDA-UCST micelles. This observation can be explained mainly by different refractive indices between the micelles and nanogels. Indeed, the light scattering intensity is much determined by the variation of the refractive index between the solvent and nanoparticles. Although the micelles and nanogels have similar compositions, the crosslinking leads to variation of the nanoparticles compactness. Several previous studies demonstrated that the swelling/collapsing of thermosensitive nanoparticles can modify their optical properties. For nanogels based on the LCST poly(N-isopropylacrylamide), the refractive index suddenly increases when temperature exceeds the phase transition temperature ${ }^{56,57}$. Inversely, for UCST-micelles, the refractive index decreases when the temperature increases beyond the phase transition temperature ${ }^{58}$. Thus, it is no surprise to observe higher light scattering intensity for crosslinked PDMA-UCST-C1 and PDMA-UCST-C2 nanoparticles, since their compactness is higher than uncrosslinked micelles. Moreover, the crosslinking introduces nickel complex in the nanogel, which also contributes to a higher refractive index. The transmittance measurements show no clear phase transition temperature for the nanogels of PDMA-UCST-C1 and PDMA-UCST-C2. Nevertheless, the measurements of the hydrodynamic diameter change in Fig. $3 \mathrm{C}$ show that the diameter increases gradually with increasing temperature before being stabilized after around $40^{\circ} \mathrm{C}$ for both nanogels, contrarily to the uncrosslinked PDMA-UCST micelles whose diameter drops. These results reveal the positive thermosensitivity of the nanogels, and their stabilized diameter above the phase transition is expected for the nanogels due to the crosslinked chains. It appears like that the 
crosslinking doesn't affect much the phase transition temperature since PDMA-UCST, PDMA-UCST-C1 and PDMA-UCST-C2 possess nearly the same transition temperatures. It is noticed that the variation of the diameter is weaker for PDMA-UCST-C2 containing more nickel-bis(dithiolene) crosslinkers. Indeed, the volume of nanogel above phase transition temperature is about 2.1 and 1.4 times larger than that at $10^{\circ} \mathrm{C}$ for PDMA-UCST-C1 and PDMA-UCST$C 2$, respectively. Finally, as shown in Fig. 3D, the crosslinked nanogels have a narrower size distribution than the uncrosslinked micelles. Regardless of the temperature, the polydispersity index is between 0.065 and 0.200 for PDMA-UCST-C1 and PDMA-UCST-C2, while the values for micelles are higher than 0.250 below phase transition temperature and strongly increase after the phase transition.

The reversibility of thermosensitive behavior for nanogels was investigated by repeating the same measurements for several heating-cooling cycles. Fig. 4A show the change in light scattering intensity and transmittance measured for PDMA-UCST-C1 (0.1 wt\% in water) at 20 and $60^{\circ} \mathrm{C}$. As shown above, the transmittance and light scattering intensity change in an opposite way. As can be seen, at $20^{\circ} \mathrm{C}$, the transmittance is low while the light scattering intensity is high, while inversely, at $60^{\circ} \mathrm{C}$, the transmittance is high and the light scattering intensity is low. The trend is similar for the variation of hydrodynamic diameter and polydispersity index, as shown in Fig. $4 \mathrm{~B}$. The nanogels evolve reversibly from their swollen to their collapse state between 20 and $60^{\circ} \mathrm{C}$ in a reproducible way over several heating and cooling cycles. Similar trends were found for PDMA-UCST-C2.

\subsection{Photothermal response and conversion efficiency}

To demonstrate the photothermal conversion efficiency of these nanogels crosslinked with a nickel-bis(dithiolene) complex, the solution temperature was recorded as a function of exposure time to laser for several light power densities. Fig. 5A to 5C show temperature rise profiles for water (for the sake of comparison) and for PDMA-UCST-C1 and PDMA-UCST-C2 dispersed in water (0.1 wt\%). From these curves, the maximal temperature reached, at thermal equilibrium, was extracted for each condition and reported in Fig. 5D. For each of the samples, the maximum increase in temperature $(\Delta T)$ increases linearly with laser power density. These trends follow that observed by Roper et al. for gold nanoparticles. They demonstrated experimentally and by calculation that the equilibrium heat flux (under irradiation) raises proportionally with the light power ${ }^{55}$. As shown in Fig. 2C, water absorbs around $980 \mathrm{~nm}$, explaining the significant temperature rising under exposure to $980 \mathrm{~nm}$ light. However, the maximum temperatures reached with the PDMAUCST-C1 and PDMA-UCST-C2 nanogels under the same conditions of light power densities are significantly higher than pure water. To further demonstrate the efficiency of photothermal conversion of these nanogels alone (without the water contribution), the same measurements were conducted in $\mathrm{D}_{2} \mathrm{O}$. As already mentioned, $\mathrm{D}_{2} \mathrm{O}$ does not absorb NIR-light and Fig. $5 \mathrm{E}$ shows that the exposure of $\mathrm{D}_{2} \mathrm{O}$ to $980 \mathrm{~nm}$ NIR-light leads to an increase of only $0.7^{\circ} \mathrm{C}$, in contrast with $\mathrm{H}_{2} \mathrm{O}$, for which a temperature increase of $19.4^{\circ} \mathrm{C}$ was obtained. With PDMA-UCST-C2 in either $\mathrm{D}_{2} \mathrm{O}$ or $\mathrm{H}_{2} \mathrm{O}$, the temperature rise is much higher, with the solution temperature reaching about $58^{\circ} \mathrm{C}(\triangle \mathrm{T}$ $\sim 40{ }^{\circ} \mathrm{C}$ ). For biomedical applications, it is important to consider the light power density used. This value has to be lower than $0.73 \mathrm{~W} / \mathrm{cm}^{2}$
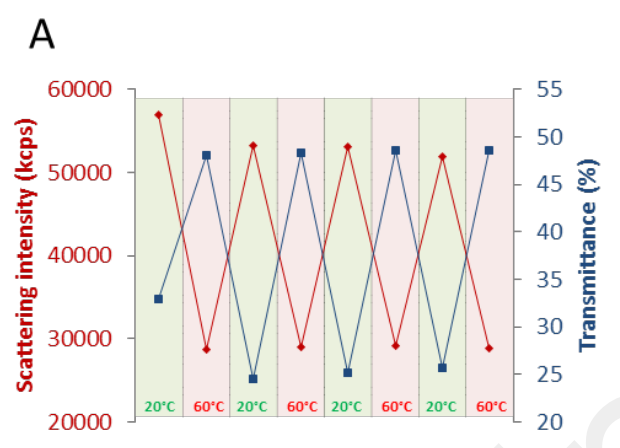

B

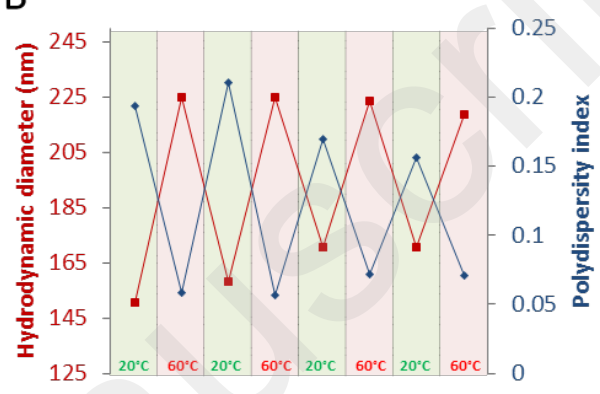

Fig. 4 Reversible thermosensitive behavior of PDMA-UCST-C1 at 0.1 wt\% in water: (A) variation of light scattering intensity and transmittance and (B) variation of hydrodynamic diameter and polydispersity index for four heating-cooling cycles from 20 to $60^{\circ} \mathrm{C}$.

for $980 \mathrm{~nm}$ light irradiation ${ }^{26,29}$. Moreover, the exposure to $980 \mathrm{~nm}$ should raise the temperature beyond $45^{\circ} \mathrm{C}$ to generate hyperthermia effect into malignant cells, but the temperature of water contained in healthy cells should be lower than $42^{\circ} \mathrm{C}$ to avoid irreversibly physicochemical damage. Thus, our photothermal nanogels may be a good candidate for related applications. Indeed, for a light power density of only $0.16 \mathrm{~W} / \mathrm{cm}^{2}$, an increase of $10^{\circ} \mathrm{C}$ is observed for PDMA-UCST-C2 nanogels while the temperature of pure water raises by about $5^{\circ} \mathrm{C}$. Under these conditions, with the body temperature as reference, it can be possible to generate a local hyperthermia effect on where the nanogels are present without damaging the surrounding where the nanogels are absent. These significant temperature increases should not only be able to generate a hyperthermia effect, but should also lead the volume transition of nanogels, allowing for the release of loaded drugs.

The response of the nanogels in aqueous solution under NIR light irradiation was thus investigated. As previously shown in Fig. 3A, direct heating of the nanogel solution results in an increase of the solution transmittance due to the volume increase (increased hydration) of the nanogels. Thus, the transmittance change of a solution of PDMA-UCST-C1 nanogels under NIR light irradiation was monitored over time. To better understand the photothermal effect, a control test was carried out by measuring the transmittance of solutions set at various temperatures using a Peltier cell only. After thermal stabilization at $24.5^{\circ} \mathrm{C}$, the temperature was increased to several defined temperatures and the transmittance was recorded over time every second upon heating. Fig. 6A shows the transmittance change profiles during the thermal equilibrium process for five different temperatures. 
A

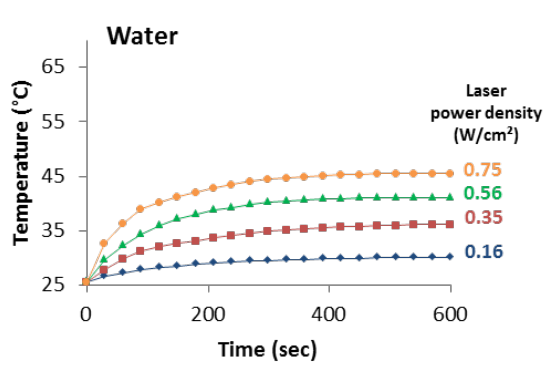

B

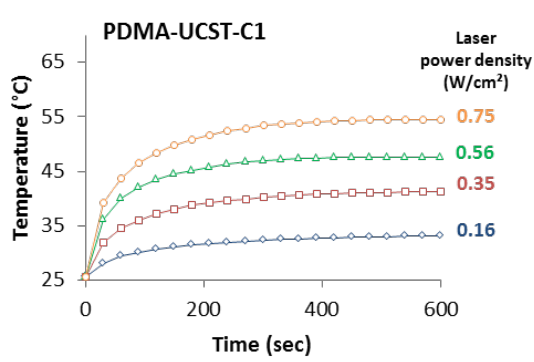

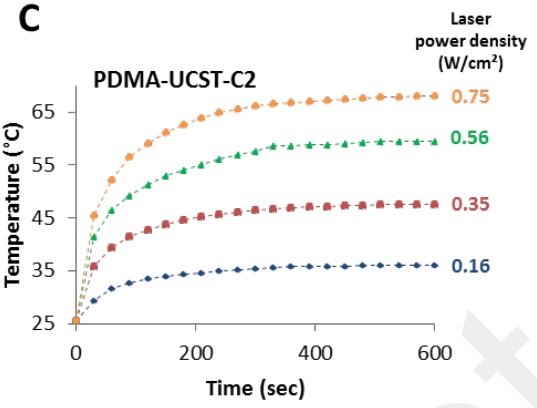

D

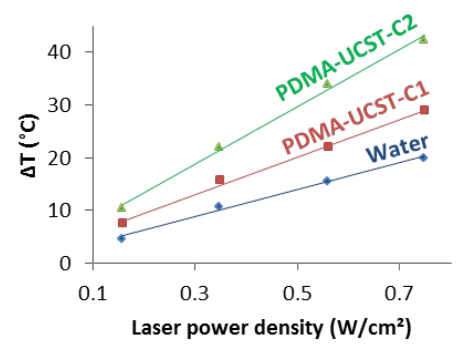

E

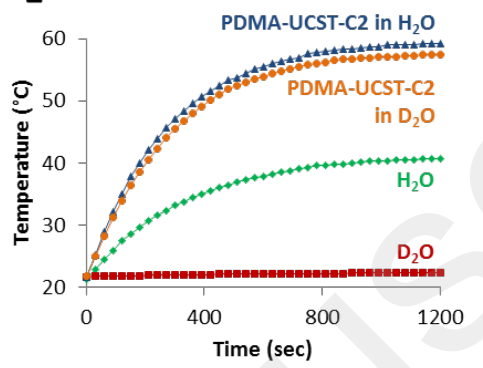

Fig. 5 Variation of temperature as a function of exposure time at several NIR laser $(980 \mathrm{~nm})$ power densities for: (A) water, (B) PDMA-UCSTC1 in water (0.1 wt\%) and (C) PDMA-UCST-C2 in water (0.1 wt\%). (D) Maximal temperatures reached at thermal equilibrium as a function of the NIR-laser power density for water (blue line), PDMA-UCST-C1 in water (0.1 wt\%) (red line) and PDMA-UCST-C2 in water (0.1 wt\%) (green line). (E) Variation of the temperature as a function of exposure time for water, deuterated water and PDMA-UCST-C2 in water and in deuterated water $\left(0.1 \mathrm{wt} \%, 0.94 \mathrm{~W} / \mathrm{cm}^{2}\right)$.

It is seen that the transmittance at equilibrium increases with the thermostated temperature. Then, the transmittance change of the nanogel solution exposed to NIR laser was also recorded over irradiation time (Fig. 6B). For those measurements, the temperature of PDMA-UCST-C1 was first adjusted to $24.5^{\circ} \mathrm{C}$ and after thermal equilibrium, the NIR-light was turned on using several light power densities. The temperature and transmittance were simultaneously recorded during 10 minutes. The transmittance change profiles are shown in Fig. 6B with the equilibrium solution temperature under irradiation indicated for each laser light power. The associated temperature change profiles under irradiation are shown in Fig. S7. Whatever the laser power density used, the transmittance reached at a given equilibrium temperature is always higher than the one obtained by direct heating. For example, for $0.75 \mathrm{~mW}$, the temperature reached at equilibrium under laser irradiation is $34.9^{\circ} \mathrm{C}$ but such transmittance value corresponds to a solution heated to almost $50^{\circ} \mathrm{C}$ as shown in Fig. $6 \mathrm{~A}$. This result implies that under NIR light exposure, the volume increase of the nanogels is greater than that would be obtained by simply heating the solution. This apparent discrepancy can be explained by a difference in heat transfer between the two sets of experiments in regard with water inside nanogels and water outside nanogels. If the sample is heated by conduction through Peltier cell (direct heating without laser), at equilibrium the temperatures of water inside and outside nanogels are identical so that the nanogel particles experience the measured solution temperature leading to the corresponding transmittance.
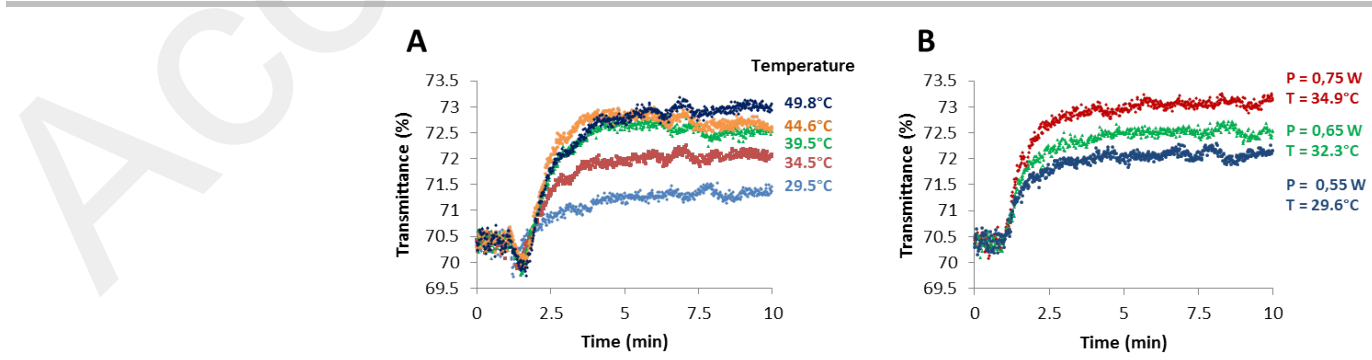

Fig. 6 (A) Variation of transmittance over time for PDMA UCST-C1 solution ( 0.1 wt\% in water) heating from $24.5^{\circ} \mathrm{C}$ to various thermostated temperatures indicated using a Peltier cell, and (B) variation of transmittance over time for PDMA-UCST-C1 solution (0.1 
wt\% in water) at $24.5^{\circ} \mathrm{C}$ exposed to various light power densities indicated (the recorded solution temperature under each laser irradiation is given underneath the laser power value).

Table 2 Photothermal conversion efficiency $(\eta)$ of PDMA-UCST-C2 for different conditions.

\begin{tabular}{cccccc}
\hline $\begin{array}{c}\text { Concentration of } \\
\text { nanogels }\end{array}$ & $\begin{array}{c}{[\mathbf{N i}]} \\
\boldsymbol{\mu g} / \mathbf{m L}\end{array}$ & $\begin{array}{c}{\left[\mathbf{N i}\left(\mathbf{S C}_{10} \mathrm{Styr}_{\mathbf{4}}\right]\right.} \\
\boldsymbol{\mu g} / \mathbf{m L}\end{array}$ & $\begin{array}{c}\text { Light power density } \\
\mathbf{W} / \mathbf{c m}^{2}\end{array}$ & Solvent & $\boldsymbol{\eta}$ \\
\hline $0.05 \mathrm{wt} \%$ & 1.29 & 30.7 & 0.54 & $\mathrm{H}_{2} \mathrm{O}$ & 0.649 \\
$0.1 \mathrm{wt} \%$ & 2.58 & 61.4 & 0.15 & $\mathrm{H}_{2} \mathrm{O}$ & 0.542 \\
$0.1 \mathrm{wt} \%$ & 2.58 & 61.4 & 0.54 & $\mathrm{H}_{2} \mathrm{O}$ & 0.540 \\
$0.1 \mathrm{wt} \%$ & 2.58 & 61.4 & 0.74 & $\mathrm{H}_{2} \mathrm{O}$ & 0.529 \\
$0.1 \mathrm{wt} \%$ & 2.58 & 61.4 & 0.54 & $\mathrm{D}_{2} \mathrm{O}$ & 0.492 \\
\hline
\end{tabular}

However, if the sample is exposed to NIR-laser source, the nickelbis(dithiolene) in the core of the nanoparticle absorbs NIR light and converts light to heat which radiates from the interior of the nanoparticle and is dissipated into the medium to reach the equilibrium solution temperature measured. In other words, the local temperature inside the nanogels or the temperature experienced by them is actually higher than the equilibrium temperature, which explains why the transmittance values under laser irradiation are higher than what is expected from the solution temperature. Note that the transmittance values reported on Figure 6 are higher than values on Figure $3 \mathrm{~A}$, for the same concentration. The origin of this difference is the path length of light $(10 \mathrm{~mm}$ vs 5 $\mathrm{mm})$.
Finally, from the temperature change profiles under NIR light irradiation, the photothermal conversion efficiency ( $\eta$ ) was evaluated for the nanogels of PDMA-UCST-C2. The $\eta$ value, corresponding to the ratio between energy dissipated as heat and radiative energy absorbed by the nanoparticles, was determined using the energy balance model described in Supporting Information. The effect of three parameters on $\eta$ was investigated, which are the light power density, the concentration of nanogel and the nature of solvent. The obtained values are reported in Table 2 . The photothermal conversion efficiency being an intrinsic parameter for each photothermal material, it is expected that a similar value is obtained by variation of light power density. By contrast, the other two parameters could affect the efficiency of light-to-heat conversion.

Table 3. Comparison of NIR photothermal conversion efficiency of the nanogels with other systems reported in the literature.

\begin{tabular}{|c|c|c|c|c|c|}
\hline Material & $\begin{array}{l}\text { Irradiation Wavelength } \\
\qquad(\mathrm{nm})\end{array}$ & $\begin{array}{l}\text { Light Power } \\
\text { Density } \\
\left(\mathrm{W} / \mathrm{cm}^{2}\right)\end{array}$ & $\begin{array}{l}\text { Concentration } \\
\qquad(\mu \mathrm{g} / \mathrm{mL})\end{array}$ & $\begin{array}{l}\eta \\
(\%)\end{array}$ & Ref. \\
\hline Au nanorods & 808 & 8 & $\leq 50$ & 98.6 & 22 \\
\hline Palladium Nanocrystals & 808 & 8 & $\leq 50$ & 93.4 & 22 \\
\hline Au-Ag alloy nanostructures & 808 & 1 & 80 & 80.4 & 59 \\
\hline $\mathrm{Ni}\left(\mathrm{SC}_{10} \mathrm{Styr}_{4}\right.$ & 980 & 0.54 & 30.7 & 64.9 & - \\
\hline Graphene Oxide & 808 & 0.2 & 1000 & 63 & 60 \\
\hline $\mathrm{Cu}_{7.5} \mathrm{~S}_{4}$ nanocrystals & 980 & 0.72 & 40 & 56.7 & 26 \\
\hline Au@Pt nanostructures & 808 & 8,85 & $\leq 500$ & 52.1 & 61 \\
\hline $\mathrm{CuFeS}_{2}$ nanocrystals & 808 & 4.92 & $\leq 20$ & 49 & 27 \\
\hline Polyaniline nanoparticles & 808 & 0.5 & $\leq 2000$ & 48.5 & 15 \\
\hline Au nanorods & 808 & 0.8 & 10 & 45.8 & 62 \\
\hline Polypyrrole nanoparticles & 808 & 1 & 20 & 45 & 63 \\
\hline $\begin{array}{l}\text { Dopamine-melanin colloidal } \\
\text { nanospheres }\end{array}$ & 808 & 2 & 200 & 40 & 64 \\
\hline Cys-CuS nanoparticles & 980 & 0.72 & 50 & 38 & 29 \\
\hline Graphene Oxide & 980 & 0.2 & 1000 & 35 & 60 \\
\hline $\mathrm{Cu}_{9} \mathrm{~S}_{5}$ Nanocrystals & 980 & 0.51 & 40 & 25.7 & 28 \\
\hline
\end{tabular}


Indeed, the diminution of the nanogel concentration from 0.1 to $0.05 \mathrm{wt} \%$ leads to an increase of the photothermal conversion value from $54.0 \%$ to $64.9 \%$. This result can be explained by a scattering effect which is more important for higher nanoparticles concentration, leading to a decrease in the absorption efficiency. On the other hand, for a nanogel concentration of $0.1 \mathrm{wt} \%$, the $\mathrm{H}_{2} \mathrm{O}$ substitution with $\mathrm{D}_{2} \mathrm{O}$ causes the decrease of the $\eta$ value from $54.0 \%$ to $49.2 \%$. This slight diminution is explained by the fact that unlike $\mathrm{H}_{2} \mathrm{O}, \mathrm{D}_{2} \mathrm{O}$ does not participate in the light-to-heat conversion process. While water is able to absorb the light at 980 $\mathrm{nm}$, deuterated water does not. As shown in Fig. 5E, with the same light power density, the exposure of water (without nanogels) to NIR-light leads to temperature increase by $19.4{ }^{\circ} \mathrm{C}$ against only $0.7{ }^{\circ} \mathrm{C}$ for deuterated water.

For NIR-sensitive systems capable of converting the radiative energy to heat, the photothermal efficiency is generally extracted from the temperature profiles measured under laser irradiation, as shown in Fig. 5. The $\eta$ values are rarely reported making any comparison difficult. Some values extracted from the literature are reported in Table 3. Our value is also inserted into this table. Despite the great disparity of concentrations and light power densities, preventing rigorous comparison, our nickel-bis(dithiolene) complex based nanogel can be classified among the most efficient NIR photothermal system. Gold nanoparticles are the most investigated and the spherical nanoparticles are the most efficient with the value near to
$100 \%$ in the visible region. However, when the shape or size increases, to obtain a localized surface plasmon resonance (LSPR) in the NIR spectral region, the photothermal conversion efficiency dramatically decreases to around $50 \%$ for gold nanorods absorbing at $808 \mathrm{~nm}$ and to $20 \%$ for gold nanorods absorbing at $1064 \mathrm{~nm}$. Our nanogels have excellent photothermal efficiency in the NIR region since, for a light power density of $0.54 \mathrm{~W} / \mathrm{cm}^{2}$ and a very low concentration to nickel element of $1.29 \mu \mathrm{g} / \mathrm{mL}(30,7 \mu \mathrm{g} / \mathrm{mL}$ of $\left.\mathrm{Ni}\left(\mathrm{SC}_{10} \mathrm{Styr}\right)_{4}\right), 65 \%$ of light energy absorbed by the system \{water + nanogel $\}$ is converted to heat. However, when $\mathrm{H}_{2} \mathrm{O}$ was substituted by $\mathrm{D}_{2} \mathrm{O}$, which is not able to absorb NIR-light, the photothermal conversion efficiency drops to $49.2 \%$ for a concentration $2.58 \mathrm{\mu g} / \mathrm{mL}$ $\left(61,4 \mathrm{\mu g} / \mathrm{mL}\right.$ of $\left.\mathrm{Ni}\left(\mathrm{SC}_{10} \mathrm{Styr}\right)_{4}\right)$. Nevertheless, this value classifies the nickel-bis(dithiolene) complex nanogel among the best for absorption of NIR light at around $1000 \mathrm{~nm}$ in NIR-1 windows.

\subsection{Loading and release of Nile Red}

To demonstrate the controlled release of hydrophobic dye induced by NIR-light from the nickel-bis(dithiolene) complex based UCSTnanogels, loading and release assays were performed. Nile Red was used as a hydrophobic dye model. The dye loading was carried out using the solvent transfer method. After calibration (Fig. S3), the loading capacities of PDMA-UCST-C1 and PDMA-UCST-C2 were 7.6 $\mu \mathrm{g}$ and $9.6 \mu \mathrm{g}$ of dye per $\mathrm{mg}$ of nanogel, respectively.
A

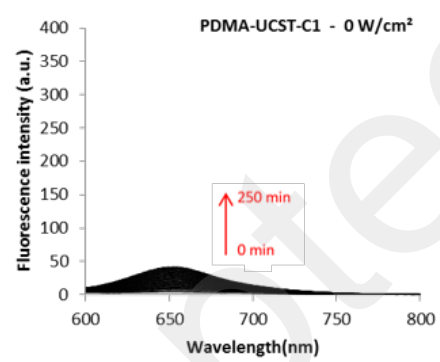

D

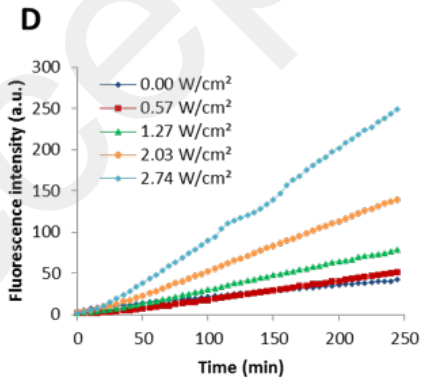

B

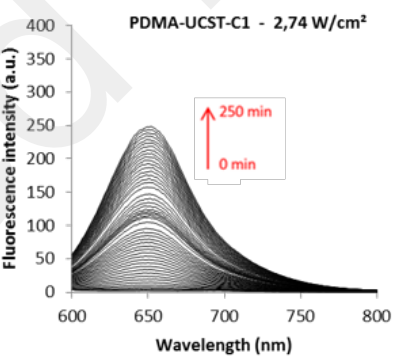

E

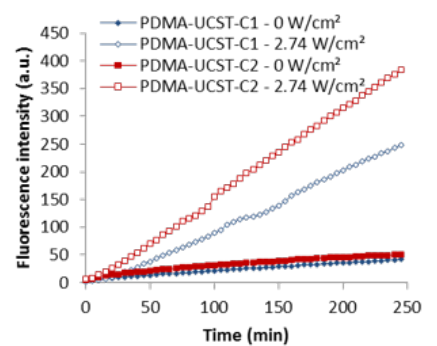

C

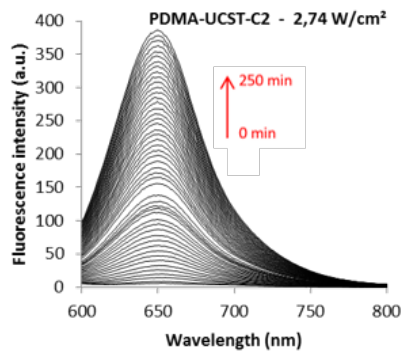

$\mathbf{F}$

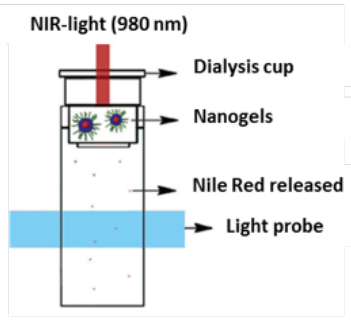

Fig. 7 Fluorescence emission spectral change of Nile Red released from nanogel solution for: (A) PDMA-UCST-C1 in the absence of NIR light, (B) PDMA-UCST-C1 under exposure to NIR-light $\left(2.74 \mathrm{~W} / \mathrm{cm}^{2}\right)$, and (C) PDMA-UCST-C2 under exposure to NIR-light (2.74 W/cm ${ }^{2}$ ). (D) Variation of fluorescence intensity of Nile Red released from PDMA-UCST-C1 solution over time under exposure to NIR light of various power densities. (E) Comparison of fluorescence intensities of Nile Red released from PDMA-UCST-C1 and PDMA-UCST-C2 solutions in the absence of NIR light and during exposition to NIR light at a same power density $\left(2.74 \mathrm{~W} / \mathrm{cm}^{2}\right)$. (F) Schematic of the experimental setup used for monitoring the fluorescence of released dye. 
A

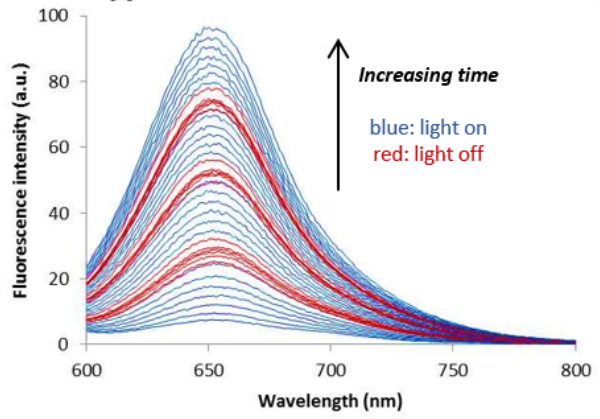

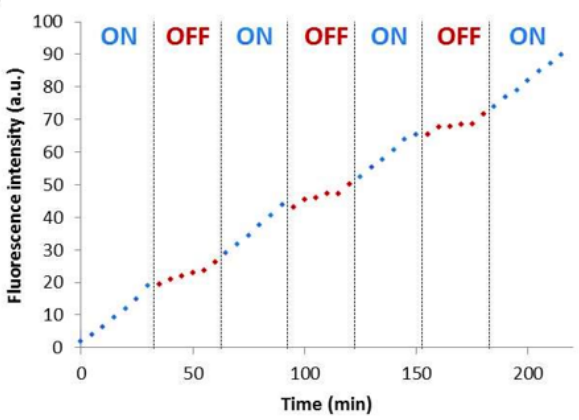

Fig. 8 (A) Fluorescence emission spectra and (B) Fluorescence intensity at $652 \mathrm{~nm}$ of Nile Red released from PDMA-UCST-C1 exposed to several NIR laser ON-OFF cycles (light power density: $2.03 \mathrm{~W} / \mathrm{cm}^{2}$ ).

The release trials were conducted using a setup presented in Fig. 7F. The dye-loaded nanogel solution was placed into a cup whose bottom is a dialysis membrane (MWCO: $12-14 \mathrm{kDa}$ ). This cup was placed into a quartz cell containing a surfactant solution (F127, 0.1 $w t \%)$, and the whole setup was placed into Peltier cell. The nanogel temperature was maintained at $20^{\circ} \mathrm{C}$ in order to preserve the same critical micellar concentration of the surfactant F127 used to solubilize the hydrophobic dye into the solution in the cell. Finally, the dialysis cup was irradiated from the top with a $980 \mathrm{~nm}$ laser and the fluorescence intensity of Nile Red in the underneath surfactant solution was recorded as a function of exposure time to NIR light for several light power densities or in absence of NIR light for the sake of comparison. Fig. 7A-7C show the evolution of Nile Red fluorescence over time under three conditions. The emission spectra for the other conditions are given in Supporting Information (Fig. S8). The fluorescence intensity over the time was extracted at $652 \mathrm{~nm}$ and reported in Fig. 7D and 7E. Fig. 7D compares the fluorescence intensities of Nile Red released from PDMA-UCST-C1 exposed to NIRlight at several light power densities, whereas, Fig. 7E compares the fluorescence intensities of Nile Red released from PDMA-UCST-C1 and PDMA-UCST-C2 exposed to the same light power density. Several observations can be made. First, without NIR light exposure, the fluorescence of Nile Red detected in the solution is weak, indicating effective trapping of the dye molecules in the nanoparticles. Secondly, under NIR light irradiation, the fluorescence emission becomes much more intense, indicating more dye molecules released from the nanogel. Moreover, the increase in fluorescence is more important when the light power density increases (Fig. 7D). As shown above in Fig. 5, the increase of light power density leads to an increase of temperature. This augmentation of temperature allows for, on the one hand, reaching higher swelling state and thus leading to decrease of trapping of the Nile Red molecules inside the polymer chains. On the other hand, an increase in temperature leads also to enhance Brownian motion that promotes the diffusion of the hydrophobic dye through the polymer chains. Thirdly, on the basis of the fluorescence emission, more dye molecules can be released from the nanogel of PDMA-UCST-C2 than from PDMA-UCST-C1 (Fig. 7E) at the same NIR light power density. Although a straightforward comparison is difficult to make because of the higher loading capacity of PDMA-UCST-C2, the results show that both nanogels are effective for NIR light induced cargo release.
Since the release is induced by NIR light as a result of the heating of the core of the nanogel particles, turning off the NIR laser should slow down the release. In order to verify the temporally controlled release, PDMA-UCST-C1 solution was exposed to successive cycles of laser ON-OFF (light power density: $2.03 \mathrm{~W} / \mathrm{cm}^{2}$ ). Fig. $8 \mathrm{~A}$ shows the evolution of fluorescence emission spectra of the Nile Red released over the time. The spectra in blue and in red correspond, respectively, to the ON and OFF state of NIR light for a period of time. From these spectra, the fluorescence intensities were extracted at $652 \mathrm{~nm}$ and reported on Fig. 8B. The result demonstrates the ability of these nanogels to release hydrophobic dye with temporal control. Indeed, the fluorescence intensity of Nile Red increases more rapidly when the laser is ON, whereas the release kinetic is highly slowed down when the light is turned off.

\section{Conclusions}

NIR light-responsive polymer nanogels with a positive thermosensitivity were obtained by crosslinking micellar aggregates of a UCST triblock copolymer, composed of acrylamide and acrylonitrile, with a molecular photothermal crosslinker, able to convert light into heat. For this purpose, a NIR photothermal nickel-bis(dithiolene) carrying four styrene functions was developed. The photothermal conversion efficiency of the nanogel was determined using the energy balance model. Depending on the conditions, the efficiency of light-to-heat conversion can reach $64 \%$, placing the nickelbis(dithiolene) complex among the most efficient photothermal agents in the NIR region around $1000 \mathrm{~nm}$. The heat generated inside the nanogels exposed to NIR light raises the temperature surrounding the nanogel particles and allows for the phase transition of the thermosensitive polymer, leading to increase in nanogel volume. This volume increase promotes the release, by diffusion, of hydrophobic molecules entrapped into the nanoparticles. The diffusion of the dye out of the polymer chains is enhanced when the light power density increases, since the temperature reached is higher leading to an increased swelling state of nanogel and to more important Brownian motion. Moreover, significant temperature increases can be obtained for very weak light power density $\left(0.16 \mathrm{~W} / \mathrm{cm}^{2}\right)$ and low concentration of nickel complex $(61.4 \mu \mathrm{g} / \mathrm{mL})$. These new 
nanogels have potential to be explored for NIR light controlled drug delivery and photothermal treatment.

\section{Conflicts of interest}

There are no conflicts to declare.

\section{Acknowledgements}

The authors acknowledge the financial support from the Natural Sciences and Engineering Research Council of Canada (NSERC) and le Fonds de Recherche du Québec: Nature et Technologies (FRQNT). YZ is a member of the FQRNT-funded Centre Québécois sur les Matériaux Fonctionnels (CQMF). FC also thanks the CNRS, the University of Rennes 1 and the Ligue Contre le Cancer Grand Ouest for financial support.

\section{Notes and references}

1 H. Yokota, Biochim. Biophys. Acta - Proteins Proteomics, 2019, 1867 (1), 17-21.

2 M. Karimi, P. Sahandi Zangabad, S. Baghaee-Ravari, M. Ghazadeh, H. Mirshekari, M. R. Hamblin, J. Am. Chem. Soc. 2017, 139, 4584-4610.

3 J. Olejniczak, C.-J. Carling, A. Almutairi, J. Control. Release, 2015, 219, 18-30.

4 H. Kim, K. Chung, S. Lee, D. H. Kim, H. Lee, WIREs Nanomed. Nanobiotechnol., 2016, 8 (1), 23-45.

5 R. Weissleder, Nat. Biotechnol., 2001, 19 (4), 316-317.

6 D. Wang, S. Wu, Langmuir, 2016, 32 (2), 632-636.

7 Y. Yuan, Z. Wang, P. Cai, J. Liu, L. De Liao, M. Hong, X. Chen, N. Thakor, B. Liu, Nanoscale 2015, 7 (7), 3067-3076.

8 Y. Liang, W. Gao, X. Peng, X. Deng, C. Sun, H. Wu, B. He, Biomaterials, 2016, 100, 76-90.

9 A. P. Gorka, R. R. Nani, J. Zhu, S. Mackem, M. J. Schnermann, J. Am. Chem. Soc., 2014, 136 (40), 14153-14159.

10 J. Xiang, X. Tong, F. Shi, Q. Yan, B. Yu, Y. Zhao, J. Mater. Chem. $B, 2018,6$ (21), 3531-3540.

11 B. Yan, J.-C. Boyer, N. R. Banda, Y. Zhao, J. Am. Chem. Soc., 2011, 133 (49), 19717-19717.

12 E. S. Shibu, M. Hamada, N. Murase, V. Biju, J. Photochem. Photobiol. C Photochem. Rev., 2013, 15 (1), 53-72.

13 D. Jaque, L. Martínez Maestro, B. Del Rosal, P. Haro-Gonzalez, A. Benayas, J. L. Plaza, E. Martín Rodríguez, J. García Solé, Nanoscale, 2014, 6 (16), 9494-9530.

14 A. Yuan, J. Wu, X. Tang, L. Zhao, F. Xu, Y. Hu, J. Pharm. Sci., 2013, $102(1), 6-28$

15 J. Zhou, Z. Lu, X. Zhu, X. Wang, Y. Liao, Z. Ma, F. Li, Biomaterials, 2013, 34 (37), 9584-9592.

16 Z. Zha, X. Yue, Q. Ren, Z. Dai, Adv. Mater., 2013, 25 (5), 777782 .

17 C. Shirata, J. Kaneko, Y. Inagaki, T. Kokudo, M. Sato, S. Kiritani, N. Akamatsu, J. Arita, Y. Sakamoto, K. Hasegawa, N. Kokudo, Sci. Rep., 2017, 7 (1), 1-8.

18 C. Yue, P. Liu, M. Zheng, P. Zhao, Y. Wang, Y. Ma, L. Cai, Biomaterials, 2013, 34 (28), 6853-6861.

19 X. Liu, G. Yang, L. Zhang, Z. Liu, Z. Cheng, X. Zhu, Nanoscale, 2016, 8 (33), 15323-15339.

20 H. Yang, H. Mao, Z. Wan, A. Zhu, M. Guo, Y. Li, X. Li, J. Wan, X. Yang, X. Shuai, H. Chen, Biomaterials, 2013, 34 (36), 91249133.

21 S. Wang, K. Li, Y. Chen, H. Chen, M. Ma, J. Feng, Q. Zhao, J. Shi, Biomaterials, 2015, 39, 206-217.
22 J. W. Xiao, S. X. Fan, F. Wang, L. D. Sun, X. Y. Zheng, C. H. Yan, Nanoscale, 2014, 6 (8), 4345-4351.

23 Z. Chen, Q. Wang, H. Wang, L. Zhang, G. Song, L. Song, J. Hu, H. Wang, J. Liu, M. Zhu, D. Zhao, Adv. Mater., 2013, 25 (14), 2095-2100.

24 S. Link, M. El-Sayed, J. Phys. Chem. B, 2002, 103 (40), 84108426.

25 Z. M. Markovic, L. M. Harhaji-Trajkovic, N. M. TodorovicMarkovic, D. P. Kepić, K. M. Arsikin, S. P. Jovanović, A. C. Pantovic, M. D. Dramićanin, V. S. Trajkovic, Biomaterials, 2011, 32 (4), 1121-1129.

26 B. Li, Q. Wang, R. Zou, X. Liu, K. Xu, W. Li, J. Hu, Nanoscale, 2014, 6 (6), 3274-3282.

27 S. Ghosh, T. Avellini, A. Petrelli, I. Kriegel, R. Gaspari, G. Almeida, G. Bertoni, A. Cavalli, F. Scotognella, T. Pellegrino, L. Manna, Chem. Mater., 2016, 28 (13), 4848-4858.

28 J. Hu, S. Yang, J. Wang, F. Jiang, M. Zhu, R. Zou, Z. Chen, J. Wang, Q. Tian, Q. Liu, ACS Nano, 2011, 5 (12), 9761-9771.

29 X. Liu, B. Li, F. Fu, K. Xu, R. Zou, Q. Wang, B. Zhang, Z. Chen, J. Hu, Dalt. Trans., 2014, 43 (30), 11709-11715.

30 M. Li, H. Yan, C. Teh, V. Korzh, Y. Zhao, Chem. Commun., 2014, 50 (68), 9745-9748.

31 M. L. Viger, W. Sheng, K. Doré, A. H. Alhasan, C. J. Carling, J. Lux, C. De Gracia Lux, M. Grossman, R. Malinow, A. Almutairi, ACS Nano, 2014, 8 (5), 4815-4826.

32 H. Ko, S. Son, S. Bae, J. H. Kim, G. R. Yi, J. H. Park, Nanotechnology, 2016, 27 (17) 175102.

33 S. Shen, B. Ding, S. Zhang, X. Qi, K. Wang, J. Tian, Y. Yan, Y. Ge, L. Wu, Nanomedicine Nanotechnology, Biol. Med., 2017, 13 (5), 1607-1616.

34 H. Gao, Y. Bi, J. Chen, L. Peng, K. Wen, P. Ji, W. Ren, X. Li, N. Zhang, J. Gao, Z. Chai, Y. Hu, ACS Appl. Mater. Interfaces, 2016, 8 (24), 15103-15112.

35 A. Halperin, M. Kröger, F. M. Winnik, Angew. Chem. Int. Ed., 2015, 54, 15342-15367.

36 M. Karimi, P. S. Zangabad, A. Ghasemi, M. Amiri, M. Bahrami, H. Malekzad, H. Ghahramanzadeh Asl, Z. Mahdieh, M Bozorgomid, A. Ghasemi, M. R. R. T. Boyuk, M. R. Hamblin, ACS Appl. Mater. Interfaces, 2016, 8, 21107-21133.

37 Z. Lu, Z. Zhang, Y. Tang, ACS Appl. Bio Mater., 2019, 2(10), 4485-4492.

38 Y. Xu, J. Chen, L. Tong, P. Su, Y. Liu, B. Gu, B. Bao, L. Wang, J. Control Release, 2019, 293, 94-103.

39 X. Qi, L. Xiong, J. Peng, D. Tang, RSC Adv., 2017, 7, 1960419610.

40 S. Shen, B. Ding, S. Zhang, X. Qi, K. Wang, J. Tian, Y. Yan, Y. Ge, L. Wu, Nanomedicine: NBM, 2017, 13, 1607-1616.

41 L. Wu, L. Zong, H. Ni, X. Liu, W. Wen, L. Feng, J. Cao, X. Qi, Y. Ge, S. Shen, Biomater. Sci., 2019, 7, 2134-2143.

42 J. Tian, B. Huang, H. Li, H. Cao, W. Zhang, Biomacromolecules, 2019, 20, 2338-2349.

43 K. Mebrouk, S. Debnath, M. Fourmigué, F. Camerel, Langmuir, 2014, 30 (28), 8592-8597.

44 K. Mebrouk, F. Chotard, C. Le Goff-Gaillard, Y. ArlotBonnemains, M. Fourmigué, F. Camerel, Chem. Commun., 2015, 51 (25), 5268-5270.

45 (a) K. Mebrouk, M. Ciancone, T. Vives, S. Cammas-Marion, T. Benvegnu, C. Le Goff-Gaillard, Y. Arlot-Bonnemains, M. Fourmigué, F. Camerel, ChemMedChem, 2017, 12 (21), 17531758. (b) M. Ciancone, N. Bellec, S. Cammas-Marion, A. Dolet, D. Vray, F. Varray, C. Le Goff-Gaillard, X. Le Goff, Y. ArlotBonnemains, F. Camerel, Langmuir, 2019, 35 (47), 1512115130

46 M. Ciancone, K. Mebrouk, N. Bellec, C. Le Goff-Gaillard, Y. Arlot-Bonnemains, T. Benvegnu, M. Fourmigué, F. Camerel, S. Cammas-Marion, J. Mater. Chem. B, 2018, 6 (12), 1744-1753.

47 A. Augé, D. Fortin, X. Tong, Y. Zhao, Polym. Chem., 2018, 9 (37), 4660-4673. 
48 L. Hou, P. Wu, Soft Matter, 2015, 11 (35), 7059-7065.

49 J. Seuring, S. Agarwal, Macromolecules, 2012, 45 (9), 39103918.

50 A. Asadujjaman, B. Kent, A. Bertin, Soft Matter, 2017, 13, 658669.

51 A. Asadujjaman, A. Bertin, A. Schönhals, Soft Matter, 2017, 13 (12), 2384-2393.

52 H. Cui, H. Kobayashi, S. Ishibashi, M. Sasa, F. Iwase, R. Kato, A. Kobayashi, J. Am. Chem. Soc., 2014, 136 (21), 7619-7622.

53 M. C. Aragoni, M. Arca, F. Devillanova, F. Isaia, V. Lippolis, A. Mancini, L. Pala, G. Verani, T. Agostinelli, M. Caironi, D. Natali, M. Sampietro, Inorg. Chem. Commun., 2007, 10 (2), 191-194.

54 T. Taguchi, H. Wada, T. Kambayashi, B. Noda, M. Goto, T. Mori, K. Ishikawa, H. Takezoe, Chem. Phys. Lett., 2006, 421 (46), 395-398.

55 D. K. Roper, W. Ahn, M. Hoepfner, J. Phys. Chem. C, 2007, 111 (9), 3636-3641.

56 B. W. Garner, T. Cai, S. Ghosh, Z. Hu, A. Neogi, Appl. Phys. Express 2009, 2 (5), 057001.

57 M. Ledesma-Motolinía, M. Braibanti, L. F. Rojas-Ochoa, C. Haro-Pérez, Colloids Surfaces A Physicochem. Eng. Asp., 2015, 482, 724-727.

58 A. Palanisamy, V. Albright, S. Sukhishvili, Chem. Mater., 2017, 29, 9084-9094.

59 Z. Liu, L. Cheng, L. Zhang, Z. Yang, Z. Liu, J. Fang, Biomaterials, 2014, 35 (13), 4099-4107.

60 O. Savchuk, J. J. Carvajal, J. Massons, M. Aguiló, F. Díaz, Carbon N. Y., 2016, 103, 134-141.

61 J. Tang, X. Jiang, L. Wang, H. Zhang, Z. Hu, Y. Liu, X. Wu, C. Chen, Nanoscale, 2014, 6 (7), 3670-3678.

62 B. Cong, C. Kan, H. Wang, J. Liu, H. Xu, S. Ke, J. Mater. Sci. Chem. Eng., 2014, 02 (01), 20-25.

63 M. Chen, X. Fang, S. Tang, N. Zheng, Chem. Commun., 2012, 48 (71), 8934-8936.

64 Y. Liu, K. Ai, J. Liu, M. Deng, Y. He, L. Lu, Adv. Mater., 2013, 25 (9), 1353-1359. 